\title{
ESTIMATION OF BBU THRESHOLD CURRENT IN AN INHOMOGENEOUS ACCELERATING SECTION
}

\author{
M.I. Ayzatsky, K.Yu. Kramarenko, V.V. Mytrochenko \\ National Science Center "Kharkov Institute of Physics and Technology”, Kharkiv, Ukraine \\ E-mail: kramer@kipt.kharkov.ua
}

In this work we describe the procedure of estimation of regenerative beam blowup threshold current in an inhomogeneous accelerating section. The self-consistent problem of transverse motion of particles in the field of dipole mode excited by the beam is solved. The distribution of dipole field near the structure axis and the energy variation of beam particles were calculated before simulating the transverse dynamics. The threshold current for S-band industrial linac designed for radiation sterilization of medical products is estimated.

PACS: 29.20.Ej

\section{INTRODUCTION}

The phenomenon referred to as beam blowup (BBU) was discovered due to observation of beam pulse shortening at the exit of accelerator at a pulse current above a certain critical value. It was found that pulse shortening is caused by beam destruction (particles are lost on disks) with preceded asymmetric growth of beam transverse dimensions. This BBU instability had been convincingly identified as interaction between the beam and the dipole deflecting mode, which is the next pass band above the accelerating mode. A regenerative BBU (R$\mathrm{BBU})$ is the BBU expected for a single-section linac. Significant efforts, both experimental and theoretical, were undertaken in order to study the detailed interaction between the dipole mode and the beam and to develop the methods of suppressing the R-BBU instability. The excitation of dipole backward waves by the continuous beam in homogeneous travelling wave accelerating sections is considered in Refs. [1 - 5]. The bunched beams and accelerating sections with losses are considered in Refs. [6 - 8]. Using different approaches the quantitative characteristics of R-BBU phenomenon such as the growth rate or e-folding time (inverse of growth rate) and the threshold (starting) current were evaluated. The R-BBU instability in tapered accelerating sections (the dipole modes are trapped) also was investigated, see Refs. $[5,9,10]$. The computed dependence of dipole mode growth rate versus beam current in SLAC injector is presented in Ref. [9]. The formula for estimating the R-BBU starting current was obtained by using the standing-wave analysis: the condition for oscillation is that the power extracted from the beam be equal to the power dissipated in the structure walls, see Refs. [5, 10]. The estimated value of starting current for $10 \mathrm{MeV} 25 \mathrm{~kW}$ industrial electron linac is presented in Ref. [11]. It was noted that although the obtained value of starting current of $\sim 2 \mathrm{~A}$ is a rough estimation, but a great margin is secured for $400 \mathrm{~mA}$ operation.

In this work we describe the procedure of estimation of regenerative beam blowup threshold current in an inhomogeneous accelerating section. The self-consistent problem of transverse motion of particles in the field of dipole mode excited by the beam is solved. The distribution of dipole field near the structure axis and the energy variation of beam particles (energy varies due to acceleration of particles) were calculated before simulating the transverse dynamics.

\section{PROBLEM FORMULATION}

A one-sectional electron linac with beam energy up to $10 \mathrm{MeV}$ (average beam power is $20 \mathrm{~kW}$ ) is under development in «Accelerator» Science and Research Establishment (see Ref. [12]). Linac is designed for radiation sterilization of medical products. The operating frequency $f_{o p}$ is $2856 \mathrm{GHz}$. Travelling wave accelerating section with integrated buncher (phase shift per cell at operating frequency is $2 \pi / 3$ ) is the inhomogeneous (tapered) disk-loaded waveguide. To estimate the RBBU threshold current we study the possibility of exponential growth of dipole mode amplitude:

$$
|h| \sim e^{\alpha t}, \quad \alpha \geq 0,
$$

where $\alpha$ is the growth rate of dipole mode amplitude. The value of the threshold current is obtained from the condition $\alpha=0$. If $\alpha<0$, then the considered dipole mode is not excited.

The frequencies and quality factors of the considered dipole eigenmodes are listed in Table 2. In Figs. 1, 2 the on-axis distributions of transverse components of electric and magnetic fields for the $1^{\text {st }}$ and $5^{\text {th }}$ eigenmodes are shown.

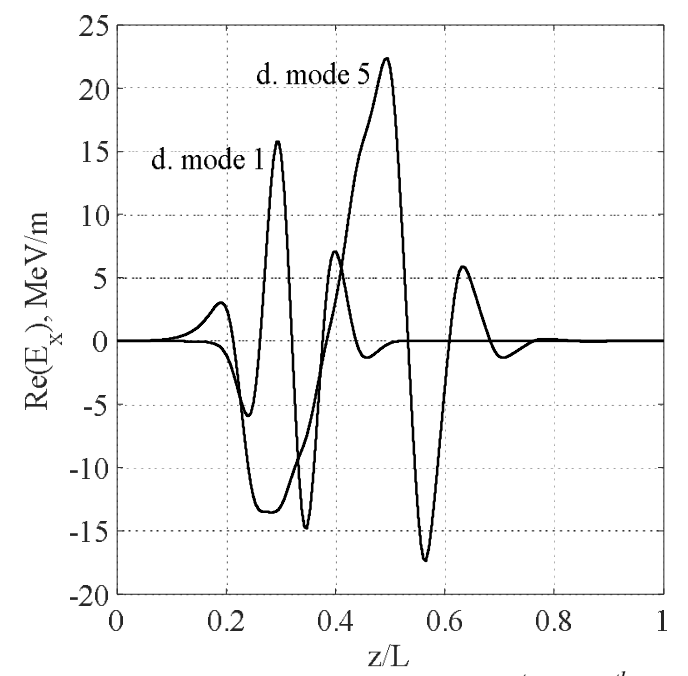

Fig. 1. $E_{x}$ on-axis distribution of the $1^{\text {st }}$ and $5^{\text {th }}$ dipole modes $\left(\operatorname{Im}\left(E_{x}\right) \equiv 0\right)$

The dependence of the energy of beam particles versus the longitudinal coordinate $z$ at the initial part of the accelerating section is shown in Fig. 3. This dependence is obtained by simulating the longitudinal dynamics of the beam particles in accelerating field. 


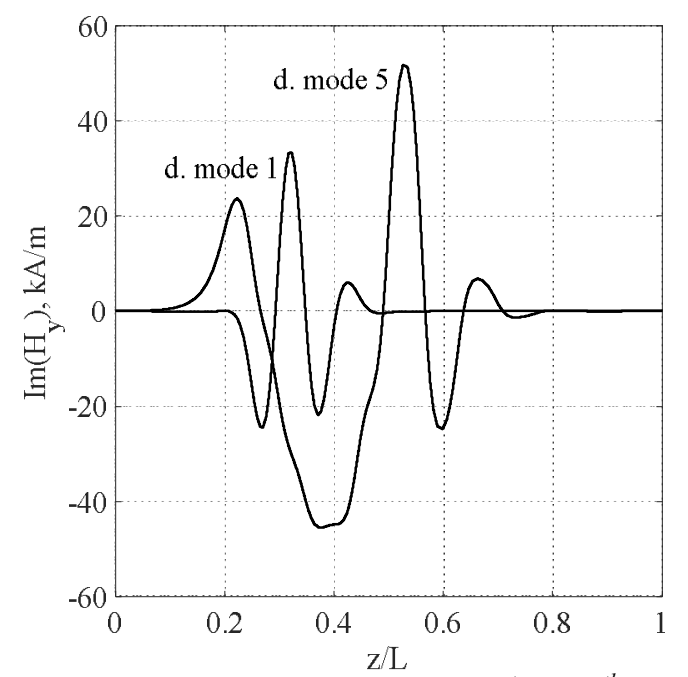

Fig. 2. $H_{y}$ on-axis distribution of the $1^{\text {st }}$ and $5^{\text {th }}$ dipole modes $\left(\operatorname{Re}\left(H_{y}\right) \equiv 0\right)$

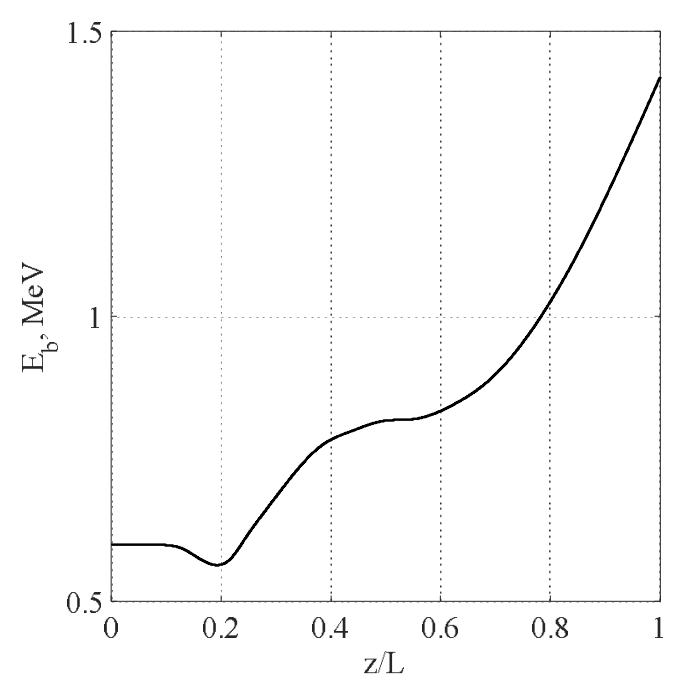

Fig. 3. Dependence of beam energy versus the longitudinal coordinate $\mathrm{z}$ at the initial part of the accelerating section

The region of accelerating section of length $L$ (see Figs. 1-3) includes drift tube, input coupler and 12 cells of integrated travelling wave buncher. Since the considered dipole eigenmodes are trapped (see Figs. 1, 2), further we will consider the region of length $L$ as a cavity (resonant volume) in which dipole modes can be excited by the beam.

The case of parametric resonance will not be considered because for each of the five modes the following condition is fulfilled: $f_{\text {res }} / f_{\text {op }} \neq 1.5$.

We made several assumptions:

- the longitudinal component of the beam velocity is much greater than the transverse one and beam current density has only longitudinal component $j_{z}$;

- the influence of dipole mode on longitudinal motion of particles is negligible and longitudinal dynamics of the beam is assumed to be determined;

- the amplitude of dipole mode do not change during the fly-time of one particle;

- at the entrance to the accelerating section the electron beam is continuous.

The interaction of beam particles with each of the five dipole modes was considered.

\section{EXCITATION OF THE DIPOLE MODE \\ BY THE BEAM AND EQUATIONS OF PARTICLE TRANSVERSE MOTION}

The electromagnetic field of dipole mode is

$$
\begin{aligned}
& \vec{E}=A(t) \vec{E}_{r e s}, \\
& \vec{H}=i B(t) \vec{H}_{r e s},
\end{aligned}
$$

where $A(t)$ and $B(t)$ are the time-dependent coefficients, $\vec{E}_{r e s}$ and $\vec{H}_{r e s}$ are the spatial distributions of electric and magnetic field of dipole mode, respectively.

The equations for $A(t)$ and $B(t)$ have the form

$$
\left\{\begin{array}{l}
\frac{d^{2} A}{d t^{2}}+\frac{\omega_{r e s}}{Q_{r e s}} \frac{d A}{d t}+\omega_{r e s}^{2} A=-\frac{1}{N_{r e s}} \frac{d J}{d t}, \\
\frac{d^{2} B}{d t^{2}}+\frac{\omega_{r e s}}{Q_{r e s}} \frac{d B}{d t}+\omega_{r e s}^{2} B=-\frac{\omega_{r e s} J}{N_{r e s}} .
\end{array}\right.
$$

Here $\omega_{\text {res }}$ and $Q_{\text {res }}$ are the dipole mode resonant frequency and quality factor, respectively, $N_{\text {res }}$ is the dipole mode norm $N_{r e s}=\varepsilon_{0} \int_{V} \vec{E}_{r e s} \cdot \vec{E}_{r e s}^{*} d V=\mu_{0} \int_{V} \vec{H}_{r e s} \cdot \vec{H}_{r e s}^{*} d V$, $J=\int_{V} j_{z} E_{r e s, z} d V, j_{z}$ is the beam current density and $E_{r e s, z}$ is the longitudinal component of electric field.

We shall consider a particular polarization of dipole eigenmode in the $x$-direction for which the longitudinal component of electric field near the axis (in the vicinity of electron stream) is of the form

$$
E_{r e s, z}=\frac{x}{r_{0}} F_{z}\left(z, r_{0}\right),
$$

where $F_{z}\left(z, r_{0}\right)$ is the longitudinal field distribution at $x=r_{0}, y=0$, and $r_{0}$ is the characteristic transverse displacement.

Expression for current density can be written as

$$
\begin{aligned}
& j_{z}=-\frac{2 \pi I_{b}}{\omega_{\text {res }} N} . \\
& \sum_{k} v_{z}(t) \delta\left(x-x_{k}(t)\right) \delta\left(y-y_{k}(t)\right) \delta\left(z-z_{k}(t)\right),
\end{aligned}
$$

where $I_{b}$ is the beam current, $N$ is the number of particles on the dipole mode period.

It will be convenient to introduce the local time. The dimensionless Lagrange time for $k^{\text {th }}$ particle is

$$
\tau_{k}=\omega_{\text {res }} t_{k}=\omega_{\text {res }} t_{0, k}+\theta_{c} \int_{0}^{\xi} \frac{d \zeta}{\beta(\zeta)},
$$

where $t_{0, k}$ is the moment of time when $k^{\text {th }}$ particle enters the cavity, $\beta(\zeta)=v_{z} / c, c$ is the velocity of light, $\xi=z / L$ is dimensionless longitudinal coordinate and

$$
\theta_{c}=\frac{\omega_{r e s} L}{c} .
$$

The solution of the system of Eqs. (3) is presented in the following form:

$$
\left\{\begin{array}{l}
A=h_{1}^{(a)}(t) e^{i \omega_{1} t}+h_{2}^{(a)}(t) e^{i \omega_{2} t}=2 \operatorname{Re}\left(h_{1}^{(a)}(t) e^{i \omega_{1} t}\right), \\
B=h_{1}^{(b)}(t) e^{i \omega_{1} t}+h_{2}^{(b)}(t) e^{i \omega_{2} t}=2 \operatorname{Re}\left(h_{1}^{(b)}(t) e^{i \omega_{1} t}\right),
\end{array}\right.
$$

where $h_{2}^{(a, b)}=h_{1}^{(a, b)^{*}}$ and 


$$
\omega_{1,2}=\frac{i \omega_{\text {res }}}{2 Q_{\text {res }}} \pm \omega_{\text {res }} \sqrt{1-\left(\frac{1}{2 Q_{\text {res }}}\right)^{2}} .
$$

Then from the system of Eqs. (3) we obtain the system of equations for $h_{1}^{(a)}(t)$ and $h_{1}^{(b)}(t)$ :

$$
\left\{\begin{array}{l}
\frac{d h_{1}^{(a)}(t)}{d t}=-\frac{e^{-i \omega_{1} t}}{2 i \omega_{r e s} N_{r e s}} \frac{d J}{d t}, \\
\frac{d h_{1}^{(b)}(t)}{d t}=-\frac{e^{-i \omega_{1} t} J}{2 i N_{\text {res }}} .
\end{array}\right.
$$

Consider the values of $h_{1}^{(a)}(t)$ and $h_{1}^{(b)}(t)$ at the moments of time

$$
t_{p}=T_{\text {res }} \cdot p
$$

where $T_{\text {res }}$ is the dipole mode period and $p=1,2,3, \ldots$.

Then from (10) we obtain:

$$
\left\{\begin{array}{l}
h_{1}^{(a)}\left(t_{p}\right)=h_{1}^{(a)}\left(t_{p-1}\right)-\frac{1}{2 i \omega_{\text {res }} N_{\text {res }}} \int_{t_{p-1}}^{t_{p}} d t \cdot e^{-i \omega_{1} t} \frac{d J}{d t}, \\
h_{1}^{(b)}\left(t_{p}\right)=h_{1}^{(b)}\left(t_{p-1}\right)-\frac{1}{2 i N_{\text {res }}} \int_{t_{p-1}}^{t_{p}} d t \cdot e^{-i \omega_{1} t} J .
\end{array}\right.
$$

We introduce the following notation

$$
h_{p}^{(a, b)}=h_{1}^{(a, b)}\left(t_{p}\right) \cdot e^{-t_{p} \omega_{r e s} / 2 Q_{r s s}} .
$$

For complex amplitudes $h_{p}^{(a)}$ and $h_{p}^{(b)}$ the following system of difference equations is obtained

$$
\begin{aligned}
& \left\{\begin{array}{l}
h_{p}^{(a)}=h_{p-1}^{(a)} e^{-\pi / Q_{r e s}}-\frac{1}{2 i \omega_{\text {res }} N_{\text {res }}} \int_{t_{p-1}}^{t_{p}} d t \cdot e^{-i \omega_{r e s} t} \frac{d J}{d t}, \\
h_{p}^{(b)}=h_{p-1}^{(b)} e^{-\pi / Q_{r e s}}-\frac{1}{2 i N_{\text {res }}} \int_{t_{p-1}}^{t_{p}} d t \cdot e^{-i \omega_{r e s} t} J .
\end{array}\right. \\
& \text { As } e^{-i \omega_{r e s} t} \cdot \frac{d J}{d t}=\frac{d}{d t}\left(e^{-i \omega_{r e s} t} J\right)+i \omega_{r e s} e^{-i \omega_{r e s} t} J \text {, then } \\
& \left\{\begin{array}{l}
h_{p}^{(a)}=h_{p-1}^{(a)} e^{-\pi / Q_{\text {res }}}-\frac{1}{2 N_{r e s}} \int_{t_{p-1}}^{t_{p}} d t \cdot e^{-i \omega_{\text {res }} t} J- \\
-\frac{1}{2 i \omega_{\text {res }} N_{\text {res }}}\left(e^{-i \omega_{\text {res }} t_{p}} J\left(t_{p}\right)-e^{-i \omega_{\text {res }} t_{p-1}} J\left(t_{p-1}\right)\right),
\end{array}\right. \\
& h_{p}^{(b)}=h_{p-1}^{(b)} e^{-\pi / Q_{r s s}}-\frac{1}{2 i N_{\text {res }}} \int_{t_{p-1}}^{t_{p}} d t \cdot e^{-i \omega_{r e s} t} J .
\end{aligned}
$$

Only particles that leave the cavity to the moment in time $t_{p}$ are taken into account when calculating values of $h_{p}^{(a)}, h_{p}^{(b)}$. Finally we obtain the following system of difference equations for complex amplitudes $h_{p}^{(a)}$ and $h_{p}^{(b)}$ :

$$
\left\{\begin{array}{l}
h_{p}^{(a)}=h_{p-1}^{(a)} e^{-\pi / Q_{r e s}}+G \sum_{\substack{k=1+\\
+N(p-1)}}^{N p} \int_{0}^{1} x_{k, n} e^{-i \tau_{k}} F_{z, n} d \xi+ \\
+i G_{a}\left(\sum_{\substack{k=1+\\
+N(p-1)}}^{\left.\sum_{k, n}^{(e n d)}-\sum_{\substack{k=1+\\
+N(p-2)}}^{N(p-1)} x_{k, n}^{(e n d)}\right)}\right. \\
h_{p}^{(b)}=h_{p-1}^{(b)} e^{-\pi / Q_{r e s}}-i G \sum_{\substack{k=1+\\
+N(p-1)}}^{N p} \int_{0}^{1} x_{k, n} e^{-i \tau_{k}} F_{z, n} d \xi .
\end{array}\right.
$$

Here $x_{k, n}=x_{k} / r_{0}$ is the normalized transverse displacement of $k$-th particle, $x_{k, n}^{(\text {end })}$ is the normalized transverse displacement of $k$-th particle at the exit of the cavity, $F_{z, n}=F_{z} / \max \left(F_{z}\right)$ and

$$
G=\frac{L I_{b} \max \left(F_{z}\right)}{2 N_{\text {res }} f_{\text {res }} N}, G_{a}=\frac{I_{b} v_{z}^{(e n d)} F_{z}^{(e n d)}}{4 \pi f_{\text {res }}^{2} N_{\text {res }} N},
$$

where $v_{z}^{(e n d)}$ is the longitudinal velocity of the particle at the exit of the cavity, $F_{z}^{(e n d)}$ is $F_{z}$ at the exit of the cavity.

It should be noted that for $p=1$ the fourth term on the right-hand side of the $1^{\text {st }}$ equation in Eqs. (16) is absent and $h_{0}^{(a, b)}=0$.

To determine the dependence of transverse displacement $x_{k, n}$ on $\xi$ for each particle, the system of equations for dipole mode amplitudes (16) should be completed by the equations of transverse motion. As relativistic factor $\gamma$ depends only on the longitudinal component of the beam velocity, the system of equations for transverse motion of $k$-th particle has the following form:

$$
\left\{\begin{array}{l}
\frac{d q_{k, x}}{d \xi}=-\frac{d \gamma}{d \xi} \cdot \frac{q_{k, x}}{\gamma}-K \frac{\operatorname{Re}\left(h_{p-1}^{(a)} e^{i \tau_{k}}\right) E_{x}^{(r e)}}{\gamma \beta}- \\
-K \frac{\operatorname{Re}\left(h_{p-1}^{(b)} e^{i \tau_{k}}\right) Z_{0} H_{y}^{(i m)}}{\gamma} \\
\frac{d x_{k, n}}{d \xi}=\tilde{K} \frac{q_{k, x}}{\beta}
\end{array}\right.
$$

where $\beta=v_{z} / c$ and $\gamma=1 / \sqrt{1-\beta^{2}}$ are the functions of $\xi$ (see Fig. 3), $E_{x}^{(r e)}$ and $H_{y}^{(i m)}$ are the on-axis distribution of electric and magnetic fields, respectively, $Z_{0}$ is the vacuum resistance; $1+N(p-1) \leq k \leq N p$ and

$$
\begin{gathered}
q_{k, x}=\frac{v_{k, x} \cdot \gamma_{0}}{v_{z, 0}}, \\
K=\frac{2 L|e|}{m_{e} c^{2}} \cdot \frac{\gamma_{0}}{\beta_{0}}, \tilde{K}=\frac{L \beta_{0}}{r_{0} \gamma_{0}} .
\end{gathered}
$$

Here $v_{z, 0}$ is the longitudinal velocity of the particles at the entrance of the cavity, $\beta_{0}=v_{z, 0} / c$, $\gamma_{0}=1 / \sqrt{1-\beta_{0}^{2}}, m_{e}$ and $|e|$ are the electron mass and charge, consequently.

To solve the equations of transverse motion, the following initial conditions are used: $q_{k, x}(0)=0$, $x_{k \neq 1, n}(0)=0, x_{1, n}(0)=1$.

Since the complex amplitudes of dipole mode $h_{p-1}^{(a)}$ and $h_{p-1}^{(b)}$ do not change during the fly-time of the particle and $\tau_{k}$ is not a function of $x_{k, n}, q_{k, n}$ (see Eq. (6)), the system of Eqs. (18) is linear.

A program for numerical solution of systems of Eqs. (16) and (18) has been written. It was tested on dipole eigenmodes of pillbox cavity for which the analytical expression of R-BBU threshold current can be obtained. 


\section{PILLBOX CAVITY. TEST CALCULATION}

Consider pillbox cavity of radius $b$ and length $d$. Beam particles are passing at the axis of the cavity with constant longitudinal velocity $v_{0}$. The electromagnetic field distribution of $\mathrm{x}$-polarized $\mathrm{TM}_{1 m p}$-mode near the axis is

$$
\begin{aligned}
& \vec{E}=\vec{e}_{z} A(t) \frac{k_{\perp} x}{2} \cos \left(k_{\|} z\right)-\vec{e}_{x} A(t) \frac{k_{\|}}{2 k_{\perp}} \sin \left(k_{\|} z\right), \\
& \vec{H}=\vec{e}_{y} B(t) \frac{\omega_{r e s}}{2 Z_{0} c k_{\perp}} \cos \left(k_{\|} z\right),
\end{aligned}
$$

where $\quad k_{\perp}=v_{m} / b, \quad k_{\|}=\pi p / d, \quad p=0,1,2 \ldots$, $\omega_{\text {res }}=c \sqrt{k_{\perp}^{2}+k_{\|}^{2}}$ is the resonant frequency, $v_{m}$ is the $m$-th root of the Bessel function $J_{1}$.

Applying the Fourier transform to the left and right parts of equations in system (3), we obtain the following system of equations for amplitudes of Fourier harmonics $A_{\omega}$ and $B_{\omega}$ :

$$
\left\{\begin{array}{l}
-\omega^{2} B_{\omega}+\frac{i \omega \omega_{\text {res }}}{Q_{\text {res }}} B_{\omega}+\omega_{\text {res }}^{2} B_{\omega}=-\frac{\omega_{r e s} J_{\omega}}{N_{r e s}} \\
-\omega^{2} A_{\omega}+\frac{i \omega \omega_{\text {res }}}{Q_{\text {res }}} A_{\omega}+\omega_{r e s}^{2} A_{\omega}=-\frac{i \omega J_{\omega}}{N_{r e s}}
\end{array}\right.
$$

where $N_{r e s}=\frac{\varepsilon_{0} \cdot \delta_{0, p}}{4}\left(\frac{\omega_{r e s} b}{c v_{m}}\right)^{2} \pi d b^{2} J_{0}^{2}\left(v_{m}\right)$,

$$
\begin{gathered}
\delta_{0, p}=\left\{\begin{array}{l}
2, p=0, \\
1, p>0
\end{array}\right. \text { and } \\
J_{\omega}=\frac{k_{\perp}}{2 \sqrt{2 \pi}} \int_{-\infty}^{\infty}\left(\int_{V} x \cos \left(k_{\|} z\right) \cdot j_{z} d V\right) e^{-i \omega t} d t, \\
x=\frac{1}{\sqrt{2 \pi}} \int_{-\infty}^{\infty} x_{\tilde{\omega}} d \tilde{\omega}, \\
j_{z}=-\frac{I_{b}}{S_{\perp}} \int_{-\infty}^{t} d t_{0} \delta\left(t-t_{l}\left(t_{0}, z\right)\right) \psi_{\perp} .
\end{gathered}
$$

It follows from the system of Eqs. (22) that $A_{\omega}=i \omega B_{\omega} / \omega_{\text {res }}$.

To obtain $x_{\tilde{\omega}}$ from Eq. (24) the following equation of transverse motion of the particle should be solved with zero initial conditions:

$$
\begin{aligned}
\frac{d^{2} x_{\tilde{\tilde{w}}}}{d \xi^{2}} & =\frac{d^{2} \cdot|e|}{m_{e} \gamma_{0} v_{0}^{2}}\left(A_{\tilde{\omega}} e^{i \tilde{\tau}} \frac{k_{\|}}{2 k_{\perp}} \sin (\pi p \xi)+\right. \\
& \left.+B_{\tilde{\omega}} e^{i \tilde{\tau}} \frac{v_{0} \omega_{r e s}}{2 c^{2} k_{\perp}} \cos (\pi p \xi)\right),
\end{aligned}
$$

where $\tilde{\tau}=\tilde{\tau}_{0}+\tilde{\theta} \xi, \quad \tilde{\tau}_{0}=\tilde{\omega} t_{0}$ is the particle injection phase at frequency $\tilde{\omega}, \tilde{\theta}=\tilde{\omega} d / v_{0}$ is the particle flyangle at frequency $\tilde{\omega} ; \xi=z / d$ is dimensionless longitudinal coordinate.

After some transformations we obtain

$$
\begin{aligned}
& \frac{\omega_{\text {res }} J_{\omega}}{N_{\text {res }} B_{\omega}}= \\
& =-\frac{\omega_{\text {res }} I_{b} k_{\perp} d}{2 N_{\text {res }} B_{\omega}} \cdot \int_{0}^{1} e^{-i \theta \xi} \tilde{x} \cos (\pi p \xi) d \xi=\Delta_{\omega},
\end{aligned}
$$

where $\tilde{x}=x_{\tilde{\omega}} e^{-i \tilde{\tau}_{0}}$.
The following characteristic equation for $\omega$ is obtained from the system of Eqs. (22):

$$
\omega^{2}-\frac{i \omega \omega_{\text {res }}}{Q_{\text {res }}}-\omega_{\text {res }}^{2}=\Delta_{\omega} .
$$

We seek the solution of characteristic Eq. (28) in the form:

$$
\omega=\omega_{\text {res }}+\delta \omega .
$$

Then using Eqs. (27) - (29) we obtain (in linear approximation):

$$
\begin{aligned}
\alpha & =-\operatorname{Im}(\delta \omega)= \\
& =-\frac{\omega_{\text {res }}}{2 Q_{\text {res }}}+\frac{I_{b} Z_{0} \beta_{0} k_{\perp}^{4} c^{4} / \omega_{\text {res }}^{3}}{\pi \delta_{0, p} v_{m}^{2} J_{0}^{2}\left(v_{m}\right) E_{0}} \cdot f(\theta) .
\end{aligned}
$$

Here $E_{0}=m_{e} c^{2} \gamma_{0} /|e|$ is the beam energy in volts, $\beta_{0}=v_{0} / c$ and

$$
f(\theta)=\frac{k_{c}^{(p)}\left((-1)^{p} \cos \theta-1\right)}{\theta}+\frac{k_{s}^{(p)}(-1)^{p} \sin \theta}{2},
$$

where

$$
\begin{gathered}
\theta=\frac{\omega_{\text {res }} d}{v_{0}}, k_{s}^{(p)}=\frac{1-\vartheta_{p}^{2} / \beta_{0}^{2}}{\left(1-\vartheta_{p}^{2}\right)^{2}}, \\
k_{c}^{(p)}=\frac{1+\vartheta_{p}^{2}-\vartheta_{p}^{2} / \beta_{0}^{2}-\vartheta_{p}^{4} /\left(2 \beta_{0}^{2}\right)}{\left(1-\vartheta_{p}^{2}\right)^{3}}, \vartheta_{p}=\frac{p \pi}{\theta} .
\end{gathered}
$$

If $f(\theta)<0$ the instability of the considered dipole mode is absent at any current.

We obtain the expression for threshold current from the Eq. (30) under the condition $\alpha=0$ :

$$
I_{\text {th }}=\frac{\pi \delta_{0, p} v_{m}^{2} J_{0}^{2}\left(v_{m}\right) E_{0}}{2 Q_{r e s} Z_{0} \beta_{0} f(\theta)} \cdot \frac{\omega_{r e s}^{4}}{k_{\perp}^{4} c^{4}} .
$$

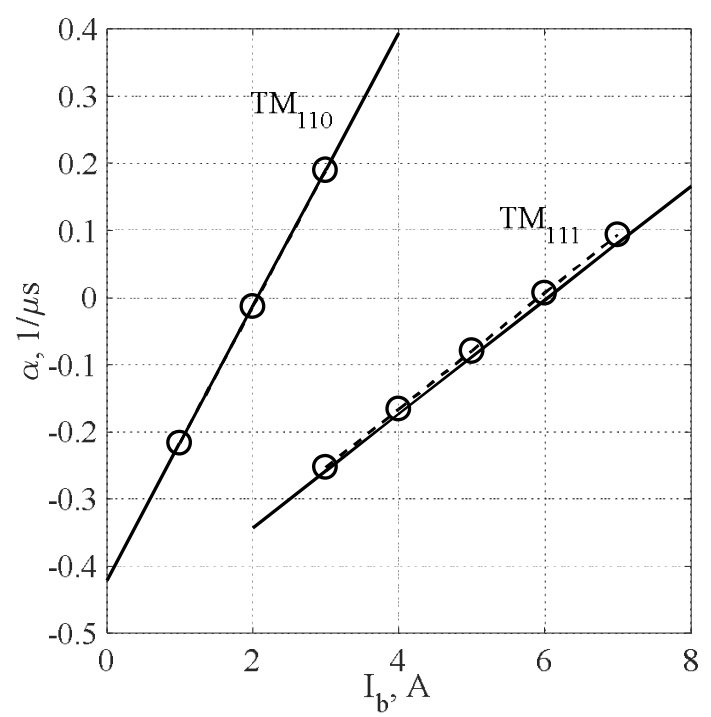

Fig. 4. Dependence of $\alpha$ ss current for $T M_{110}(b=4 \mathrm{~cm}$, $d=20 \mathrm{~cm})$ and $T M_{111}(b=4 \mathrm{~cm}, d=17.8 \mathrm{~cm})$ modes

in pillbox cavity at beam energy of $1 \mathrm{MeV}$; solid line - Eq. (30), circ. - systems of Eqs. (16), (18)

The dependencies of $\alpha$ versus current for $\mathrm{TM}_{110}$ and $\mathrm{TM}_{111}$ modes in pillbox cavity at electron beam energy of $1 \mathrm{MeV}$ are shown in Fig. 4. These dependencies are obtained from numerical solutions of Eq. (30) and systems of Eqs. (16), (18), where 


$$
\alpha=\frac{\ln \left|h_{p}^{(b)}\right|-\ln \left|h_{p-1}^{(b)}\right|}{T_{\text {res }}} .
$$

Threshold current values are given in Table 1.

Table 1

$R$-BBU threshold current for dipole modes in pillbox cavity $(b=4 \mathrm{~cm})$ at beam energy of $1 \mathrm{MeV}$

\begin{tabular}{|c|c|c|c|c|}
\hline \multirow{3}{*}{$d, \mathrm{~cm}$} & \multicolumn{4}{|c|}{ Threshold current, A } \\
\hline & & $\Lambda_{110}$-mode & & $\mathrm{U}_{111}$-mode \\
\hline & Eq.(34) & Eqs.(16), (18 & Eq.(34 & Eqs.(16), (18 \\
\hline 17.8 & - & - & 6.04 & 5.92 \\
\hline 20.0 & 2.06 & 2.07 & - & - \\
\hline
\end{tabular}

As one can see from Fig. 4 and Table 1 different procedures give R-BBU quantitative characteristics that are in good agreement.

\section{SIMULATION}

According to the problem formulation we have been performed the numerical calculations of the systems of Eqs. (16), (18) for the first five dipole modes which are trapped in the initial part of the accelerating section (see Figs. 1,2). The dependencies of $\alpha$ versus current are shown in Fig. 5. From Fig. 5 it follows that for the first mode $\alpha_{1} \geq 0$ at $I \geq I_{t h}$. For all other modes $\alpha_{2-5}<0$ at any beam current. Thus only the first dipole mode can be excited by the beam in the accelerating section (beam energy variation is shown in Fig. 3). The R-BBU threshold current value is shown in Table 2 .

$R$-BBU threshold current for dipole modes in the accelerating section

\begin{tabular}{|c|c|c|c|}
\hline d. m. & $f_{\text {res }}, \mathrm{GHz}$ & $Q_{\text {res }}$ & $I_{\text {th }}, \mathrm{A}$ \\
\hline 1 & 3.785729 & 9561.5 & 6.3 \\
\hline 2 & 3.821361 & 9841.1 & - \\
\hline 3 & 3.871112 & 10113 & - \\
\hline 4 & 3.932035 & 10507 & - \\
\hline 5 & 3.991609 & 11049 & - \\
\hline
\end{tabular}

The estimated value of threshold current is $\sim 6 \mathrm{~A}$. Since the value of operating current is $400 \mathrm{~mA}$ there is a small possibility to obtain the unstable beam dynamics.

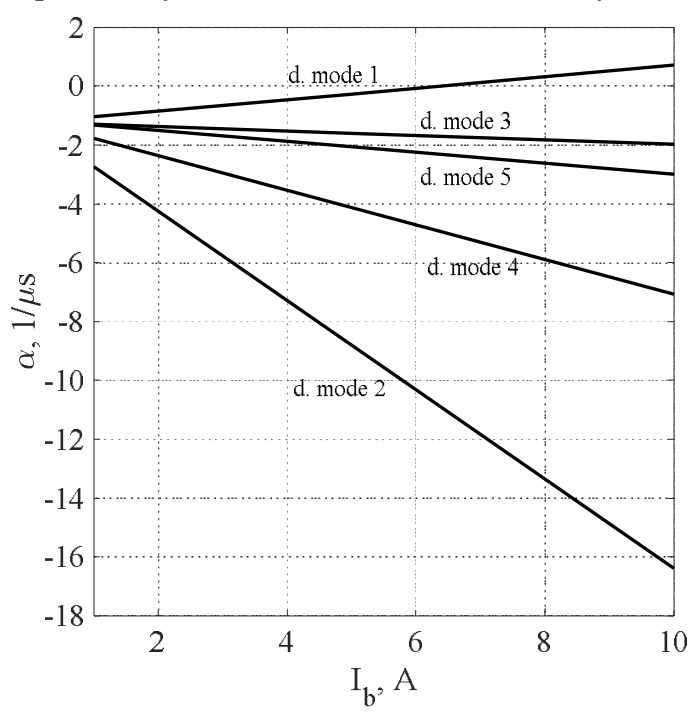

Fig. 5. Dependence of $\alpha$ vs current for dipole modes in the cavity

\section{CONCLUSIONS}

The procedure of estimation of R-BBU threshold current in tapered accelerating sections is presented. The estimated value of threshold current for electron linac which is under development in "Accelerator» Science and Research Establishment is 6.3 A.

\section{REFERENCES}

1. H. Hirakava. Pulse Shortening Effect in Linear Accelerators // Japanese Journal of Applied Physics. 1964, v. 3, № 1, p. 27-35.

2. R.L. Gluckstern. Transverse Beam Blow-up in Standing Wave Linacs // Proc. of Linear Accelerator Conference. 1964, p. 186-203.

3. T.R. Jarvis, G. Saxon, M.C. Crowley-Milling. Experimental Observations of Pulse Shortening in a Linear-Accelerator Waveguide // Proceedings of the Institution of Electrical Engineers. 1965, v. 112, № 9, p. 1795-1802.

4. J.E. Bjorkholm, R.F. Hyneman. An Analysis of $\mathrm{TM}_{11}$ Mode Beam Blowup in Linear Electron Accelerators // IEEE Trans. Elect. Dev. 1965, v. 12, № 5, p. 281-288.

5. P.B. Wilson. High Energy Electron Linacs: Applications to Storage Ring RF Systems and Linear Colliders // slac-pub-2884 (Rev.), 1991.

6. G.V. Voskresenskiy, Yu.N. Serebryakov. Development of Electron Beam Transverse Instability in Linear Accelerator // Atomnaya energiya. 1968, v.25, №6, p. 507-513 (in Russian).

7. G.D. Kramskoy, V.I. Kurilko, V.A. Shendrik. Transverse Beam Instability in Single Resonator Section // Journal of Technical Physics. 1973, v. 43, № 12, p. 2609-2616.

8. N.I. Ayzatskiy. Accounting for Reflections of Axially Nonsymmetric Waves from the Ends of Sections When Describing the Development of Transverse Instability // Voprosy Atomnoy Nauki $i$ Tehniki. Series "Tehnika fizicheskogo eksperimenta”. 1982, №2 (11), p. 18-20 (in Russian).

9. R. Helm. Computer Study of Wave Propagation, Beam Loading and Beam Blowup in the SLAC Accelerator // Proc. of Linear Accelerator Conference. 1966, p. 254-266.

10. P.M. Lapostolle, A.L. Septier. Linear accelerators. Amsterdam: "North-Holland Publ. Co". 1970, p. $173-221$.

11. Y. Kamino. $10 \mathrm{MeV} 25 \mathrm{~kW}$ Industrial Electron Linac // Proc. of XVIII International Linac Conference. 1996, p. 836-838.

12. M.I. Ayzatsky, E.Z. Biller, A.N. Dovbnya, et al. Accelerating Section for Technological Electron Linac // Problems of Anomic Science and Technology. Series "Nuclear Physics Investigations". 2016, № 3, p. $38-44$.

Article received 19.02.2020 


\section{ОЦЕНКА ПОРОГОВОГО ТОКА ПОПЕРЕЧНОЙ НЕУСТОЙЧИВОСТИ ПУЧКА В НЕОДНОРОДНОЙ УСКОРЯЮЩЕЙ СЕКЦИИ}

Н.И. Айзацкий, Е.Ю. Крамаренко, В.В. Митроченко

Описана процедура оценки порогового тока поперечной неустойчивости пучка в неоднородной ускоряющей секции. Решается самосогласованная задача поперечного движения частиц в поле дипольной моды, которая возбуждается пучком. Распределение дипольного поля вблизи оси структуры и изменение энергии частиц были рассчитаны до моделирования поперечной динамики. Проведена оценка порогового тока для промышленного линейного ускорителя S-диапазона, предназначенного для радиационной стерилизации медицинской продукции.

\section{ОЦІНКА ПОРОГОВОГО СТРУМУ ПОПЕРЕЧНОЇ НЕСТІЙКОСТІ ПУЧКА В НЕОДНОРІДНІЙ ПРИСКОРЮВАЛЬНІЙ СЕКЦІї}

\section{М.І. Айзацький, К.Ю. Крамаренко, В.В. Митроченко}

Описано процедуру оцінки порогового струму поперечної нестійкості пучка в неоднорідній прискорювальній секції. Вирішується самоузгоджена задача поперечного руху частинок у полі дипольної моди, яка збуджується пучком. Розподіл дипольного поля поблизу осі структури і зміна енергії частинок були розраховані до моделювання поперечної динаміки. Проведено оцінку порогового струму для промислового лінійного прискорювача S-діапазону, призначеного для радіаційної стерилізації медичної продукції. 